
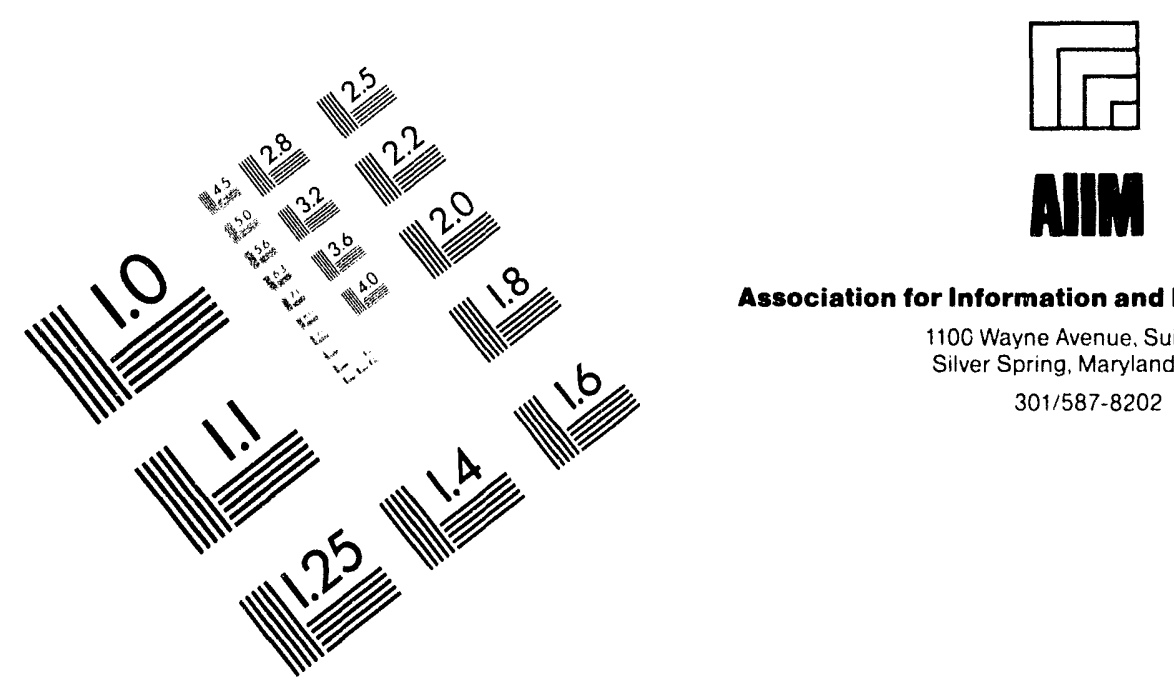

Association for Information and Image Management

1100 Wayne Avenue. Suite 1100

Silver Spring, Maryland 20910

301/587-8202

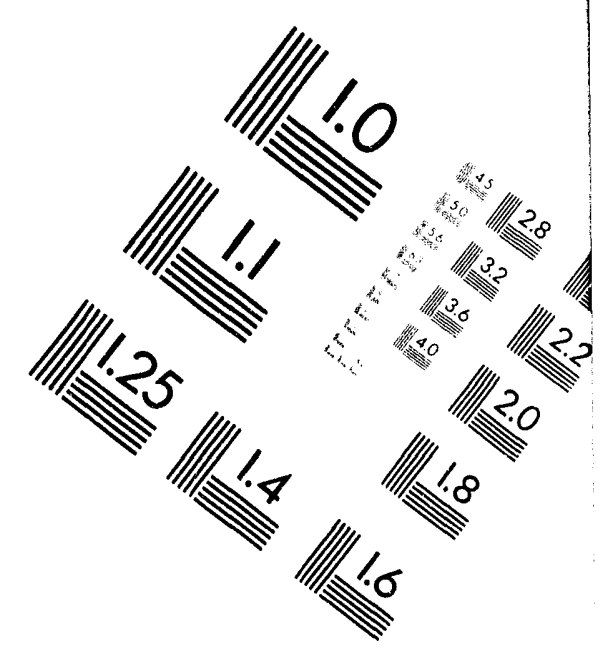

\title{
Centimeter
}

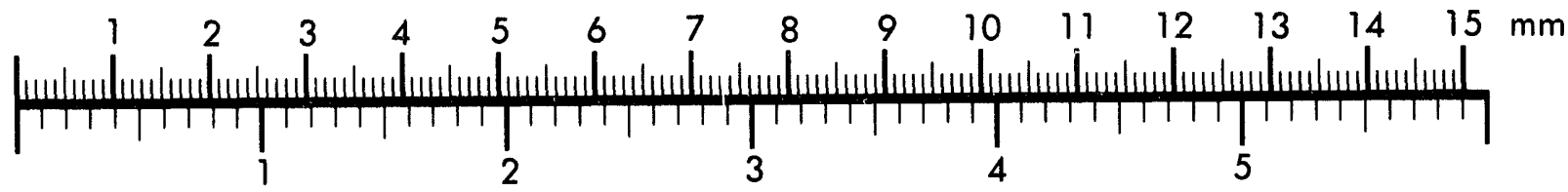

Inches
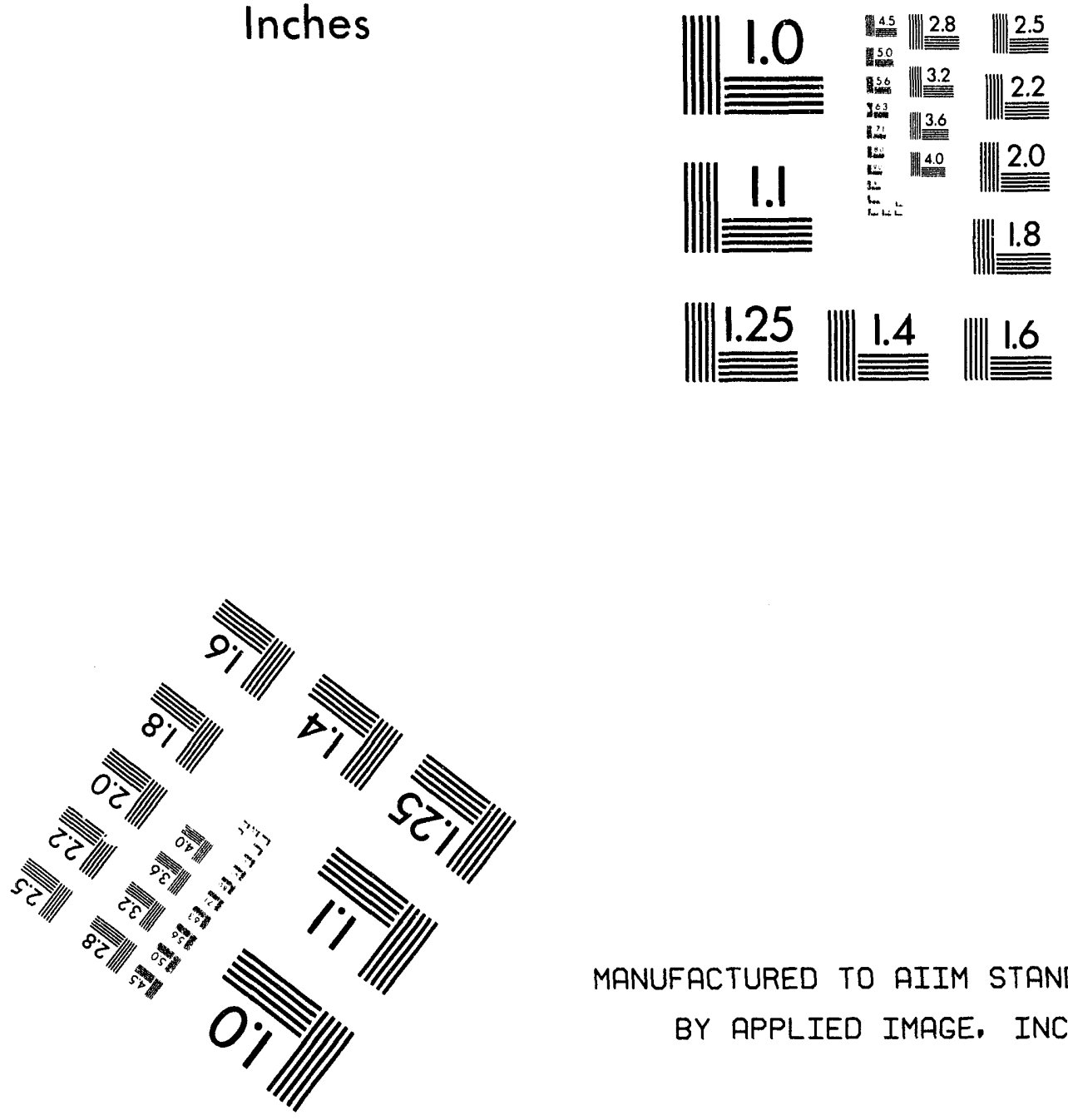

MANUFACTURED TO AIIM STANDARDS

BY APPLIED IMAGE. INC.

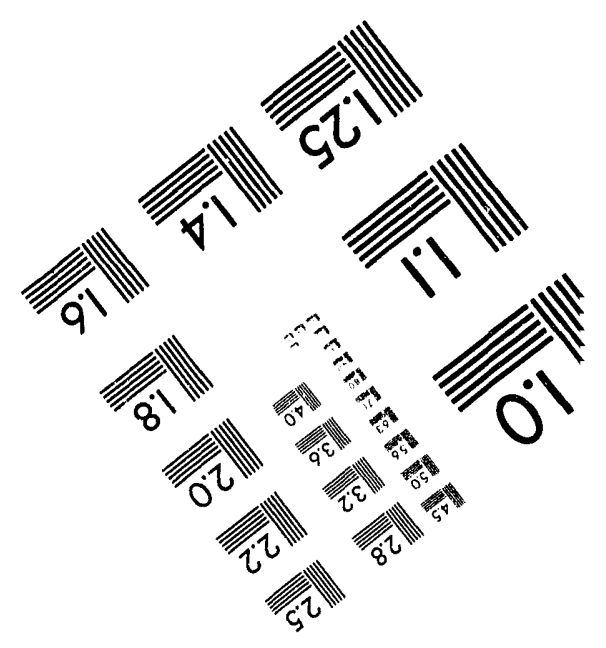



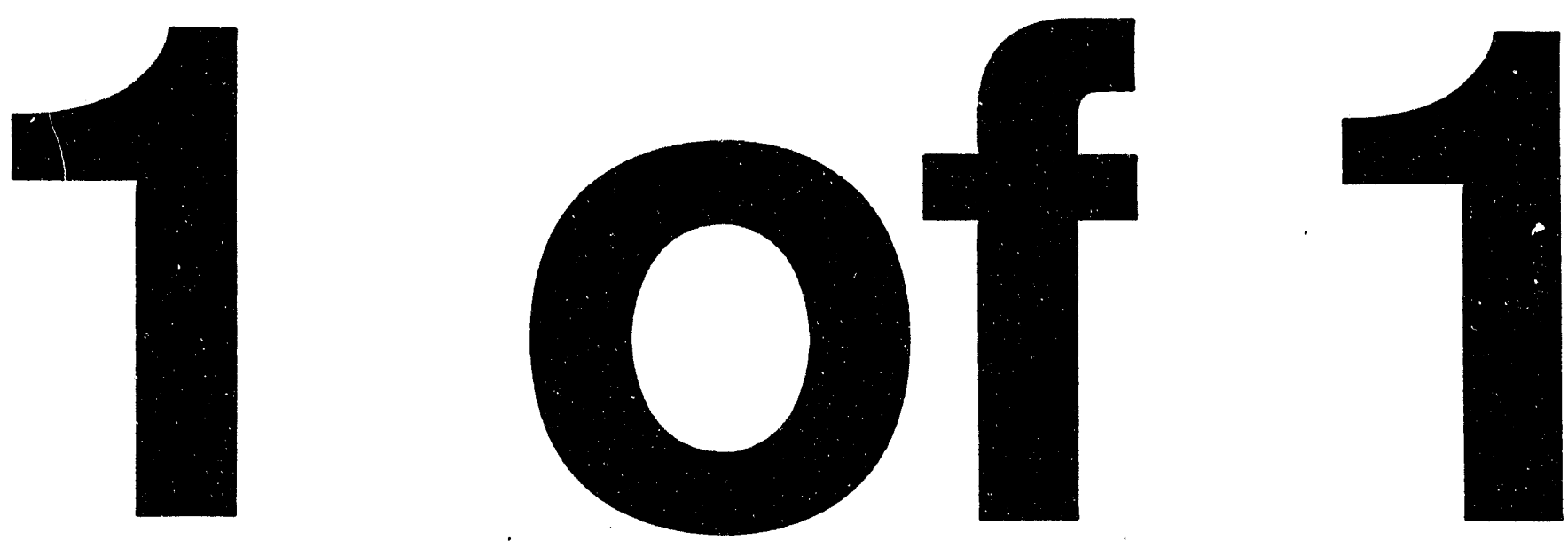
PNL-SA-24365

\section{FLUID DYNAMIC EFFECTS ON PRECISION CLEANING WITH SUPERCRITICAL FLUIDS}

\section{DISCLAIMER}

M. R. Phelps

M. O. Hogan

L. J. Silva

June 1994
This report was prepared as an account of work sponsored by an agency of the United States Government. Neither the United States Government nor any agency thereof, nor any of their employees, makes any warranty, express or implied, or assumes any legal liability or responsibility for the accuracy, completeness, or usefulness of any information, apparatus, product, or process disclosed, or represents that its use would not infringe privately owned rights. Reference herein to any specific commercial product, process, or service by trade name, trademark, manufacturer, or otherwise does not necessarily constitute or imply its endorsement, recommendation, or favoring by the United States Government or any agency thereof. The views and opinions of authors expressed herein do not necessarily state or reflect those of the United States Government or any agency thereof.

Presented at the

JANNAF Conference

June 14-15, 1994

Indian Head, Maryland

Prepared for

the U.S. Department of Energy

under Contract DE-AC06-76RLO 1830

Pacific Northwest Laboratory

Richland, Washington 99352 


\title{
Fluid Dynamic Effects on Precision Cleaning with Suprercritical Fluids ${ }^{1}$
}

\author{
M.R. Phelps, M.O. Hogan, L.J. Silva \\ Pacific Northwest Laboratory ${ }^{2}$ \\ Richland, WA 99352
}

\begin{abstract}
Pacific Northwest Laboratory staff have assembled a small supercritical fluids parts cleaning test stand to characterize how system dynamics affect the efficacy of precision cleaning with supercritical carbon dioxide. A soiled stainless steel coupon, loaded into a "Berty" autoclave, was used to investigate how changes in system turbulence and solvent temperature influenced the removal of test dopants. A pulsed laser beam through a fiber optic was used to investigate real-time contaminant removal. Test data show that cleaning efficiency is a function of system agitation, solvent density, and temperature. These data also show that high levels of cleaning efficiency can generally be achieved with high levels of system agitation at relatively low solvent densities and temperatures. Agitation levels, temperatures, and densities needed for optimal cleaning are largely contaminant dependant. Using proper system conditions, the levels of cleanliness achieved with supercritical carbon dioxide compare favorably with conventional precision cleaning methods. Additional research is currently being conducted to generalize the relationship between cleaning performance and parameters such as contaminant solubilities, mass transfer rates, and solvent agitation. These correlations can be used to optimize cleaning performance, system design, and time and energy consumption for particular parts cleaning applications.
\end{abstract}

\section{INTRODUCTION}

Degreasing is an essential manufacturing process, particularly in industries fabricating or assembling metal parts. Degreasing is widely used co remove oil and oil-borne solids from parts ranging from transistors, precision equipment, and printed-circuit assemblies to large aircraft and automotive parts. Degreasing is used both as an intermediate process, where gross cleaning is needed for ease of production, and as a final production process, where precision cleaning is required before painting, bonding, or plating.

Critical cleaning is contaminant removal to the $\mu \mathrm{g} / \mathrm{cm}^{2}$ level where surface films are measured to within a few angstroms. Parts requiring critical cleaning include gyroscope bearing surfaces, computer disk surfaces, and precision electronic and optical parts. Critical cleaning typically involves several tinses in an appropriate solvent where very little or no solvent residue remains on the surface of the part being cleaned.

Chlorofluorocarbons (CFCs) have been widely used for precision cleaning of metal parts, circuit boards, and other equipment. CFCs are inert, pure solvents that leave very little residue on the surfaces of the parts being cleaned. However, the production of CFCs is rapidly being phased out according to the 1987 Montreal Protocol agreement due to concerns about stratospheric ozone depletion.

Hydrochlorofluorocarbons (HCFCs) have been proposed as a substitute to CFCs. However, at the 1990 London environmental summit, the Montreal Protocol agreement was amended to restrict the use of HCFCs also. The new agreement calls for using HCFCs only when other, less ozone-destructive alternatives are not available.

Approved for public release; distribution is unlimited. 
The new agreement also calls for the complete phasing out of HCFCs by 2020 .

Aqueous emulsion cleaning (AEC) is one alternative to the use of CFCs and HCFCs that does not use chlorinated or ozone depleting solvents. However, aqueous cleaning may not be a suitable alternative for many cleaning applications due to the difficulty of completely eliminating a surface residue. Use of AEC solvents such as detergents, terpenes, and ethanolamines can also present serious health and safety risks to cleaning system operators due to known or suspected toxicities. Also, because cleaning efficiency deteriorates with loading, AEC solvents, and similarly CFCs and HCFCs, must either be regenerated or disposed of when solvent loading occurs. Although the residual from solvent reclamation contains mostly oils and oil-borne particulates, it frequently has to be disposed of as a hazardous waste because of the presence of the solvent.

An attractive alternative to degreasing with CFCs, HCFCs and AEC is precision cleaning with supercritical fluids. Supercritical fluids parts cleaning (SFPC) makes use of the unique solvent characteristics of fluids near and above their critical point to remove contaminants from the surfaces of metal and possibly plastic parts. Supercritical fluids approach the density and solvating power of the fluid in the liquid phase while maintaining the viscosity and flow characteristics of the fluid in the gaseous phase. Thus, supercritical fluids typically maintain viscosities an order of magnitude less and diffusivities an order of magnitude greater than liquids of similar density ${ }^{\prime}$. These properties can be dramatically modified by slight changes in fluid density, which is a strong function of changes in pressure and temperature in the near-critical and supercritical range. For any particular contaminant, a slight drop in solvent pressure significantly reduces its solubility in a supercritical fluid. Therefore, it is possible to solubilize a mixture of contaminants from the surface of a part and then selectively reclaim, through slight variations in pressure, each individual contaminant. By dropping the solvent pressure far eno'sgh, all contaminants can be separated from the solvent, and the solvent can be reclaimed for reuse.

Supercritical carbon dioxide is especially attractive as a solvent for SFPC. Carbon dioxide exists naturally as an environmentally safe, non-flammable, inert gas that, except in extreme cases, poses no threat to exposed personnel. Carbon dioxide is also readily available and relatively inexpensive to use. The critical temperature for carbon dioxide is $31^{\circ} \mathrm{C}$ [ $88^{\circ} \mathrm{F}$ ], and the critical pressure is 73.8 bar [1070 psi]. Above the critical temperature, the fluid cannot be compressed enough to force the formation of a liquid phase. At or near the critical pressure, density of the fluid becomes very pressure dependent; a pressure increase of $50 \%$ can produce a four-fold density increase ${ }^{2}$. Therefore, supercritical fluids such as carbon dioxide can be compressed to near liquid-like densities where they can display good solvent properties.

The use of supercritical fluids as alternative solvents has been of interest for many years. The phenomena of increased solubility in supercritical fluids compared to gases is becoming well known. However, developing large-scale applications requires knowledge of cleaning or mass transfer rate parameters as well as equilibrium solubility information. Design of commercial applications requires the scaling up of small-scale tests with similar equipment. To avoid scale-up of SFPC systems from strictly empirical information, engineering data linking system performance with process parameters are needed ${ }^{3}$. These data will ultimately be used to reduce the risk of scale-up by providing the design engineer(s) with empirical correlations between easily measured or estimated process parameters (flow rate, density, pressure, and temperature) and a performance-based objective (mass transfer rate).

Pacific Northwest Laboratory (PNL), with Boeing Aerospace Company and Inland Technology, is working on development and scale-up of a process to clean manufactured parts using supercritical fluid solvents 4 . This project is part of a collaborative program that also includes Los Alamos National Laboratory (LANL), Sandia National Laboratories (SNL), and other industrial partners to address the technology development issues inhibiting rapid commercialization of SFPC.

\section{EXPERIMENTAL EQUIPMENT AND METHODS}

PNL has assembled a small SFPC test stand to characterize how system dynamics affect the efficacy of 
cleaning with supercritical carbon dioxide. Several series of experiments were performed to determine the effects of turbulence, solvent temperature, solvent density, and system pressure. The experimental objectives were to establish relationships between the solubility of the contaminating species, changes in solvent temperature, density, system agitation, and cleaning efficiency. An additional matrix of tests was performed to measure the effestiveness of supercritical carbon dioxide cleaning as compared to standard solvent cleaning procedures currently in use.

\section{EQUIPMENT}

The bench-scale SFPC test stand, shown in Figure 1, consists of a medium-pressure, high-temperature autoclave (constructed by Autoclave Engineers and modified for these tests) and supporting equipment to achieve supercritical cleaning. Carbon dioxide, supplied to the system from standard compressed gas bottles, enters the system through a constant-temperature water bath where condensation occurs at $15^{\circ} \mathrm{C}\left[60^{\circ} \mathrm{F}\right]$. A refrigeration cooler maintains the temperature at the pump head and in the line from the constant-temperature bath to the pump head. Temperature at the pump head must be maintained to ensure that fluid entering the pump is a liquid. Liquid carbon dioxide is then fed through the top and into the autoclave where it is pumped to operating pressure by a high-pressure liquid chromatography (HPLC) precision metering pump. Pressure in the autoclave is controlled by a back pressure regulator located downstream of the autoclave. Flow through the autoclave is from top to bottom. A separator vessel collects the dopant as it disengages from the carbon dioxide on pressure letdown. Decontaminated carbon dioxide leaving the separator is recycled directly into the feed.

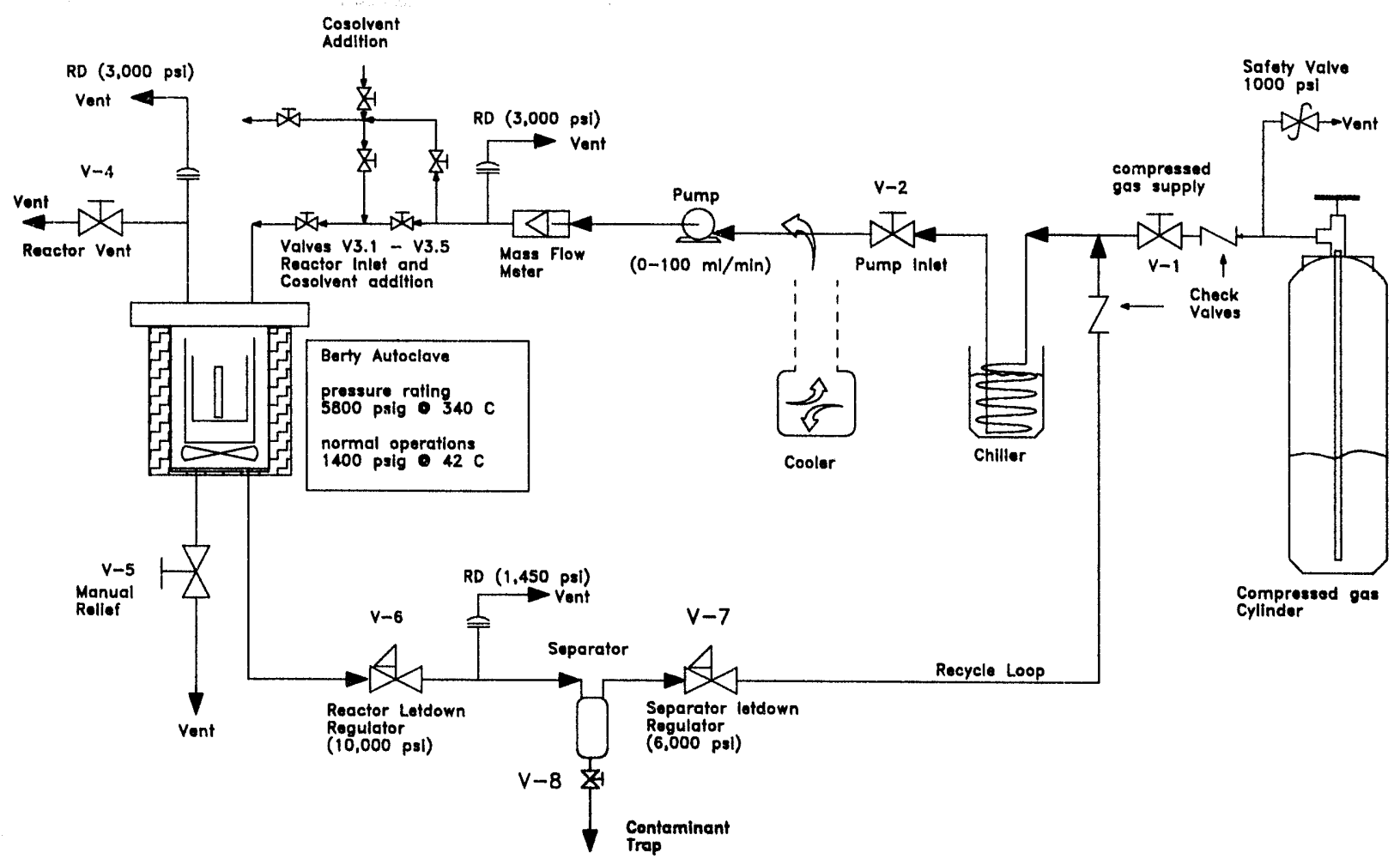

Figure 1. Supercritical Fluid Parts Cleaning test stand.

The autoclave, shown in Figure 2a, is a 433-cc, $76 \mathrm{~mm}$ [3-inch] I.D., fixed-bed catalytic reactor constructed by Autoclave Engineers (a "Berty" autoclave). Agitation in the autoclave is supplied by an impeller attached through the bottorn of the autoclave to a MagnaDrive assembly. The autoclave rests in a ceramic heater assembly that is capable of heating the autoclave to temperatures greater than $500^{\circ} \mathrm{C}$. Rated pressure of the autoclave is $400 \mathrm{bar}$ [5800 psi] at $340^{\circ} \mathrm{C}\left[944^{\circ} \mathrm{F}\right]$. Power to the heaters is supplied through a Variac which can be manually adjusted 
during testing to control temperature. Impeller speed is controlled by a variable speed controller that is part of the MagnaDrive unit. The only modifications to the autoclave necessary for our testing was to change the MagnaDrive bushings from carbon to nylon, perform a complete polishing of all the interior surfaces of the autoclave, and to fashion a coupon holder to position the coupon in the autoclave in the same orientation for every test run.

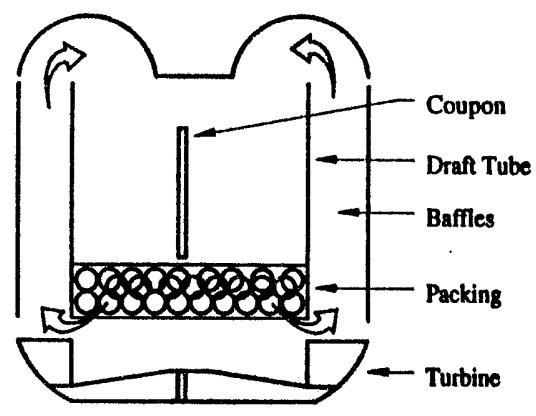

(a)

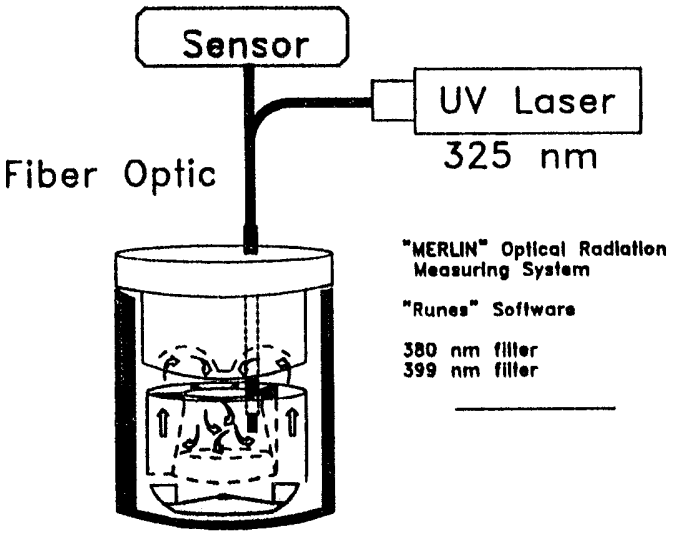

(b)

Figure 2. (a) An internal view of the Berty autoclave showing the flow profile. (b) Orientation of fiber optic / laser system in autoclave.

A fiber optic/laser system, shown in Figure 2b, was used with the SFPC test stand to observe cleaning rates in real-time. The system is composed of a Liconix helium/cadmium laser, its power supply, and other peripheral equipment necessary for its operation. A $1-\mathrm{mm}$ diameter silica optical fiber simultaneously sends laser-generated light into the autoclave and returns fluorescence signals from inside the autoclave. Signals returned from the autoclave are picked up by a photomultiplier tube and sent to a signal conditioning unit which gives a readout as fluorescence intensity in voltage units. From the signal conditioning unit, a signal was also sent to a computer loaded with "Runes" software. This software plots fluorescence intensity vs. time. The optical fiber is inserted through the lid of the autoclave and is secured with a high-pressure compression fitting. This allows removal and reinsertion of the fiber before and after each run.

Test contaminants for our experiments were selected based on two criteria. First, the contaminants, after being cleaned in the SFPC test stand, must leave a measurable residue under some of the cleaning conditions within the range of our experiments. Comparison of different system conditions in terms of the degree of contaminant removal is necessary to establish optimum process conditions. Second, the contaminants must be approximately as difficult to remove as real contaminants. Initial testing determined the best compounds to serve as contaminants for the series of cleaning efficacy experiments. From this testing, two candidates fitting the criteria were selected: Dow Corning $^{\otimes} 200$ fluid and Castle/Sybron X-448 High-temperature Oil. The Dow Corning Fluid is a poly(dimethyl)siloxane fraction with a viscosity of $100 \mathrm{cSt}$ and an average molecular weight of about 5000 . The $\mathrm{X}-448$ Oil is a polybutene/mineral oil mixture.

A Mettler AE200 analytical balance was used to perform gravimetric analyses for the various experiments. Reproducibility for this balance is specified at $\pm 0.1 \mathrm{mg}$. 


\section{EXPERIMENTAL PROCEDURES}

\section{Coupon Contamination Procedures}

For each series of experiments, the same stainless steel coupon $(4 \mathrm{~cm} \times 3.5 \mathrm{~cm} \times 0.1 \mathrm{~cm})$ was precleaned, coated with the test contaminant, and then placed in the autoclave tor testing. For precleaning, the coupon was either cleaned first in a chloroform bath, rinsed with acetone, and then dipped in an acetone bath, or cleaned in a 1,1,1-trichloroethane bath and then wiped with a tissue to remove any residue. After precleaning, the coupon was weighed to ensure that cleaning had been accomplished to within the limits of our analytical balance.

For the first two series of experiments, the coupon was submerged completely in one of the two test contaminants, patted lightly with a Kim Wipe to remove excess material, and weighed. Loading was controlled to 0.005 grams from run to run to minimize effects of surface concentration differences.

In later series, dopants were applied to one side of the coupon which was marked to designate an area so that the contaminated area would remain constant from run to run. The contaminants were applied to this area with a small short-bristled paint brush. Contaminant mass for each of these series was kept constant from run to run to within \pm 0.0001 grams.

\section{Coupon Cleaning with Gravimetric Analysis}

After applying the contaminant, the coupon was loaded into the preheated autoclave by placing the coupon onto a holder that kept the coupon in a vertical position. The autoclave's top was then bolted on and the test started.

The autoclave vessel and system were filled with carbon dioxide to the first back-pressure regulator, and residual air was vented from the system through a valve at the top of the autoclave. Once the system was filled, the pump was started at an average feed rate of $57 \mathrm{ml} / \mathrm{min}$ of liquid carbon dioxide. For testing at supercritical conditions, timing began when the pressure gauge at the top of the autoclave reached 1100 psi.

When the autoclave pressure reached $1100 \mathrm{psig}$, the impeller was turned on to a predetermined speed. The autoclave pressure was allowed to reach and maintain operating pressure for the remainder of the test run. Approximately 15 seconds before the end of the run, the carbon dioxide supply was turned off and the system vented. When the system pressure dropped to $1100 \mathrm{psig}$, the impeller was turned off. Pressure letdown typically took 15 seconds. One volume turnover for the autoclave (internal volume $=433 \mathrm{ml}$ with baffles and basket in place) is estimated at 7.5 minutes.

After the carbon dioxide was removed from the system, the coupon was removed from the system and immediately weighed on the same analytical balance that was used for contaminant loading.

\section{Photometric Analysis of Surface Contamination}

Real-time observation of surfact cleaning was accomplished by using the fiber optic tip as the surface to be cleaned. Baselines of both test contaminants were taken to test fluorescence of the pure compounds. Results from these tests showed that the laser did not cause the silicone oil to fluoresce. A series of mixtures of different fluorescing compounds were made up. These consisted of $1.03 \times 10^{-4} \mathrm{M}$ concentrations each of 1-hexadecylpyrene, 1-pyrenedodecanoic acid, 1-pyrenenonanil, and pyrene in silicone oil. After testing each of these mixtures to obtain the optimum signal (high enough fluorescence with a minimum of background noise), the $1.03 \times 10^{-4} \mathrm{M} 1$ hexadecylpyrene in silicone oil was selected as the test contaminant. With the fiber optic inside the autoclave, datalogging of the fluorescence signal was initiated using the "Runes" program. Temperatures, pressures, and solvent flow rates were recorded at regular intervals throughout each run and all runs were 10 minutes long. 


\section{Solubilities of Test Contaminants In Carbon Dioxide}

A view cell with block heaters and a temperature controller was used to obtain solubility information for the selected test contaminants. Carbon dioxide was supplied to the cell directly from the HPLC pump on the SFPC test stand; process piping was rerouted for these experiments. Two temperatures were selected at which data would be taken for construction of a phase diagram. In each run, the heaters were turned on and the cell allowed to reach the desired temperature. The cell was filled with a predetermined amount of the test contaminant, flushed with a small amount of carbon dioxide, and sealed. The pump was turned on and allowed to fill with carbon dioxide. When pressures reached 346 to 415 bar [5000 to $6000 \mathrm{psig}$ ], the pump was turned off, the contents were allowed to mix, and the cell temperature was allowed to stabilize around the set point. After recording the starting pressure, the contents were let out of the cell by opening a high-pressure valve. This was done slowly enough to keep the temperature at the set point and to be able to discern to within a few psig at what pressure phase transition occurred. Phase transition pressures, temperatures, and solute amounts were recorded for each run.

\section{RESULTS}

Figure 3 shows the relationship between the average mass flux of contaminant and system agitation. For equal cleaning intervals, contaminant removal rates increase as the impeller speed increases up to a maximum efficacy, which depends on the contaminant. The maximum efficacy for a 5-minute cleaning run was reached for silicone oil at a lower impeller speed than for high-temperature oil. Increasing system turbulence beyond this point does not improve mass flux, and would be a waste of power. Weight differentials were used to determine mass flux of dopant from the coupon. Impeller speed was used to calculate the impeller Reynolds number for stirred-vessel agitations.

Impeller Reynolds Number

$$
R e=\frac{D_{a}^{2} N \rho}{\mu}
$$

$$
\begin{array}{ll}
D=\text { impeller diameter } & \mathrm{m} \\
N=\text { rotational speed } & \mathrm{rev} / \mathrm{s} \\
\rho=\text { fluid density } & \mathrm{kg} / \mathrm{m}^{3} \\
\mu=\text { viscosity } & \mathrm{kg} / \mathrm{m}^{*} \mathrm{~s}
\end{array}
$$

To relate impeller speed to an actual velocity inside the draft tube (Figure 2), a correlation that relates pumping capacity of an arrowhead-type impeller to its diameter was used ${ }^{6}$.

$$
q_{p}=0.556 N d^{3}
$$

$$
\begin{array}{ll}
\mathrm{q}_{\mathrm{p}}=\text { volumetric flow rate of fluid leaving the impeller } & \mathrm{m}^{3} / \mathrm{s} \\
\mathrm{N}=\text { rotational speed } & \mathrm{rev} / \mathrm{s} \\
\mathrm{d}=\text { impeller diameter } & \mathrm{m}
\end{array}
$$

Assuming that $100 \%$ of the fluid leaving the impeller is sent through the draft tube, we can calculate the average velocity inside the draft tube. Inserting the impeller diameter and dividing by the cross-sectional area of the draft tube, our equation relating impeller speed to average velocity $\left(v_{n}\right.$ in $\left.\mathrm{m} / \mathrm{s}\right)$, is:

$$
v_{a}=0.083 N
$$




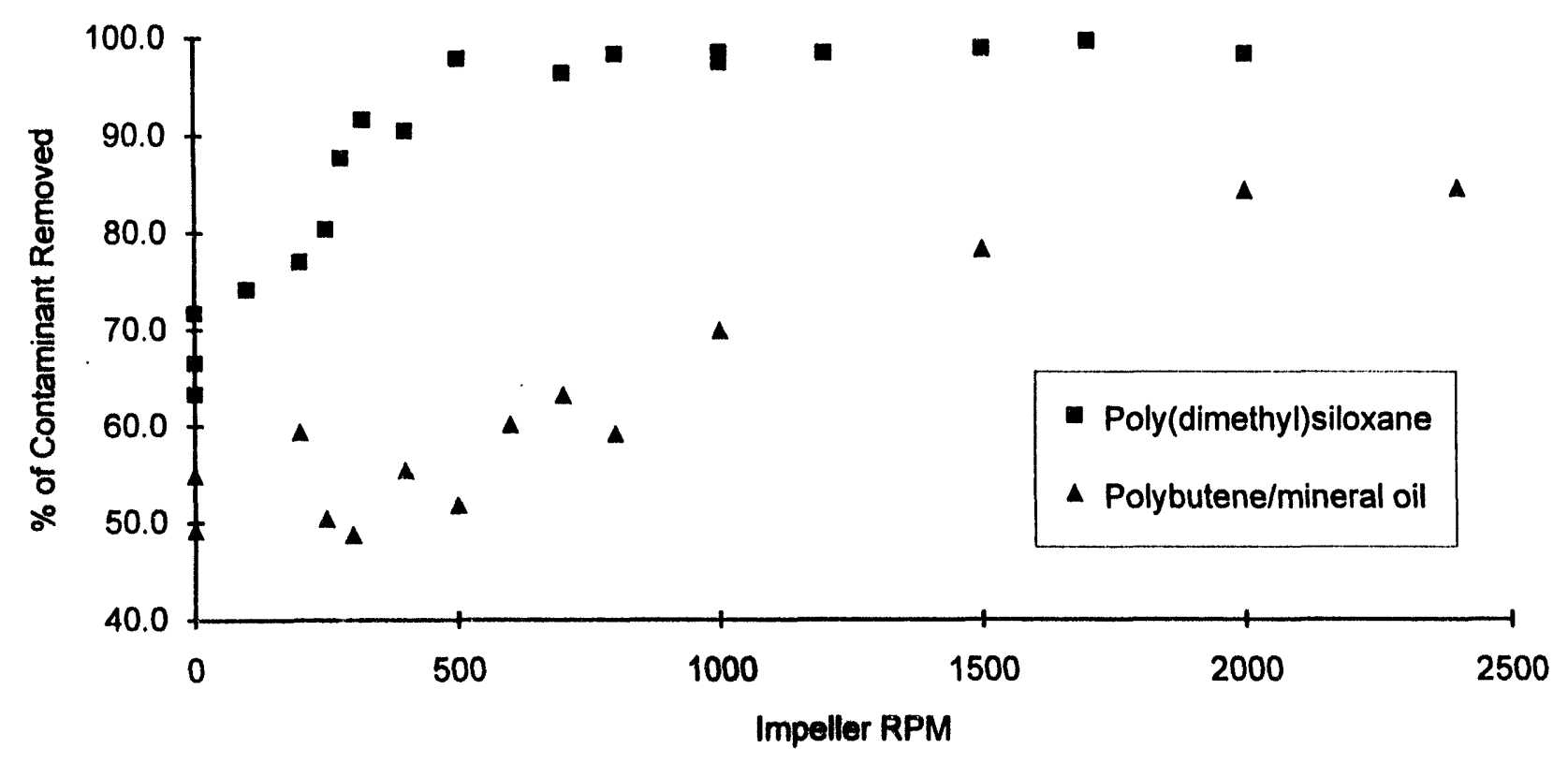

Figure 3. Plot of test data; average contaminant removal for 5 minute runs vs. impeller speed.

Optically Stimulated Electron Emission (OSEE) results (Figure 4) shows that surface cleanliness for coupons cleaned by supercritical carbon dioxide compare very favorably to coupons cleaned by conventional critical cleaning methods.

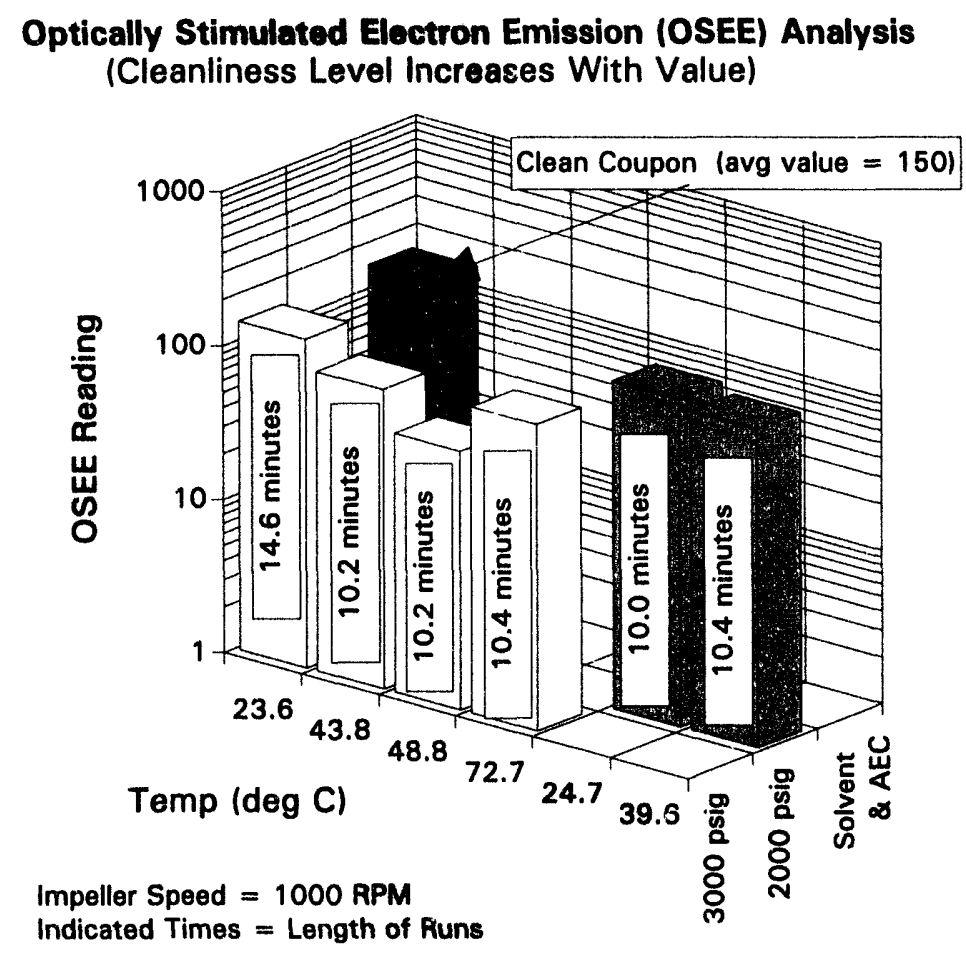

Figure 4. OSEE analysis of SFPC cleaning. 
Experiments at supercritical conditions using the fiber optic / laser system show that, as the impeller speed is increased, the contaminant is removed more rapidly. However, at subcritical conditions, the dependence of removal on system agitation was much less marked. Figure 5 shows time of removal decreasing with increased impeller speed for two different levels of cleaning.

\section{Contaminant Removal as a Function of Time and Impeller Speed}

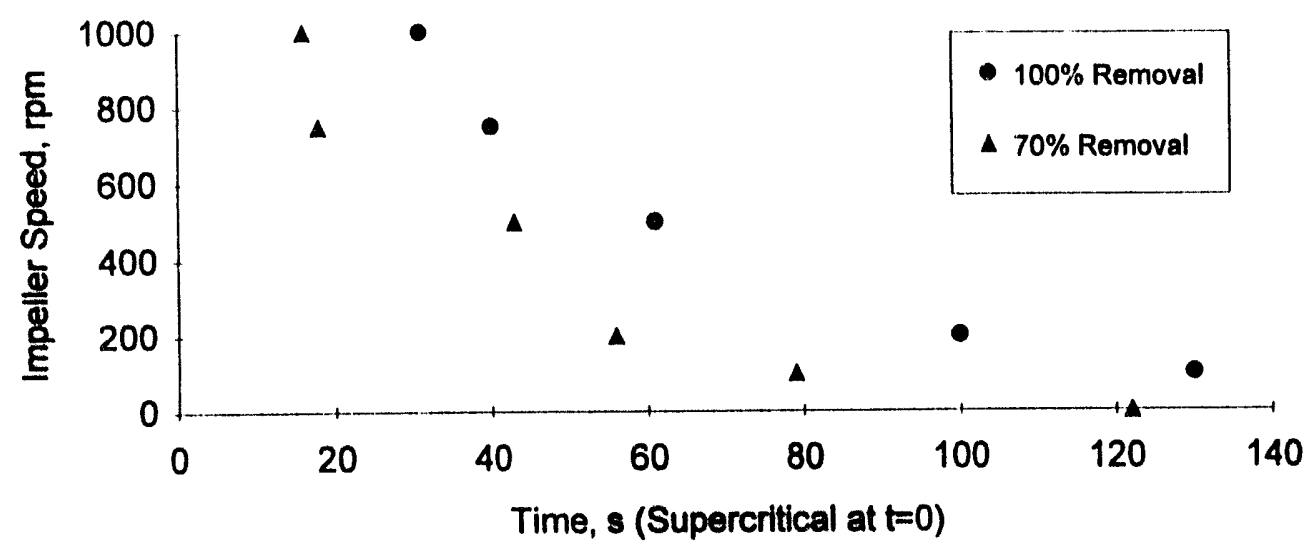

Figure 5. Removal of contaminant from silica substrate shown as a function of system agitation.

The last series of experiments reveal that high impeller speeds at low pressures give cleaning comparable to low or zero impeller speeds at higher pressures. As the impeller speed is increased, Figure 6 shows that contaminant removal becomes much less dependent on both pressure and density.

(a)

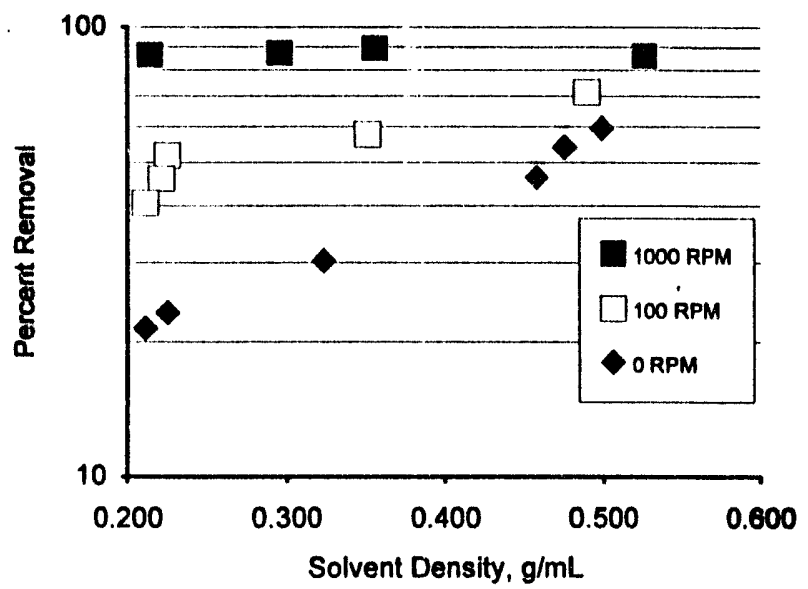

(b)

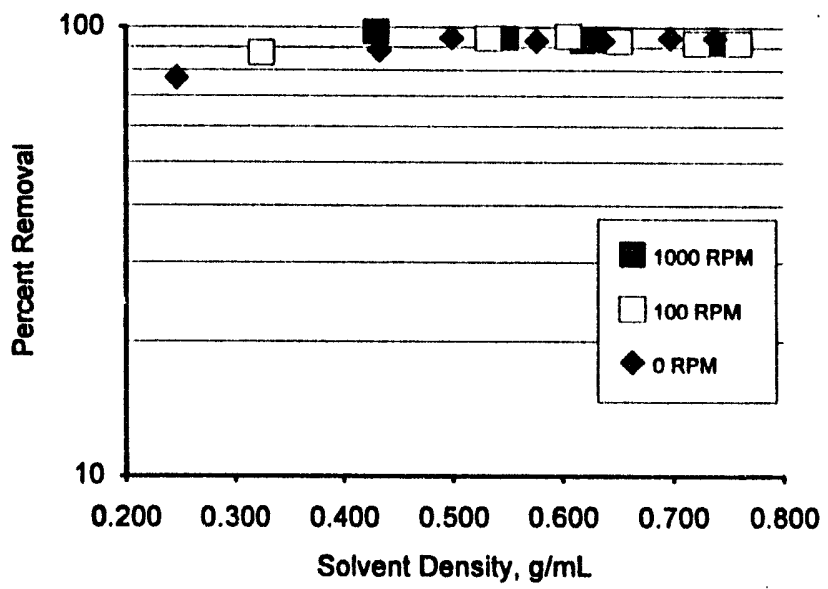

Figure 6. Plots showing removal of foly(dimethyl)siloxane from a stainless steel coupon as a function of solvent density and impeller speed. (a) Operating pressure $=1200$ psig. (b) Operating pressure $=2000$ psig.

\section{CONCLUSIONS}

Because results from these experiments show that system agitation has a pronounced effect both on overall contaminant removal and the mass flux from the contaminated surface, the use of agitation in commercial cleaning 
systems should, wherever possible, be used. It is well known that many substances exhibit a marked increase in solubility in the higher pressure regions as shown in Figure $7^{7}$. However, the cost of equipment increases significantly as process pressure increases.

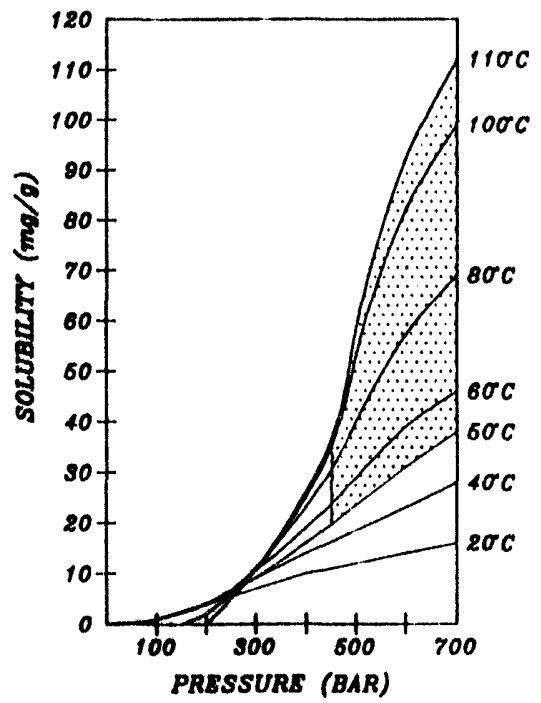

Figure 7. Solubility curves calculated for soybean oil in supercritical carbon dioxide as a function of pressure at various temperatures. Note the "Enhanced Solubility Region" (shaded area).

Because agitation in a system allows lower pressures for comparable cleaning (Figure 6), the cost of such systems can be greatly reduced. Table 1 is a cost comparison calculation ${ }^{8}$ for 20 -galion, vertical mount pressure vessels, rated for temperatures from -20 to $750^{\circ} \mathrm{C}$.

Table 1. A cost comparison of two pressure vessels with maximum allowable workir $\&$ pressures of 1500 and 5000 psi.

\begin{tabular}{|c|c|c|}
\hline $\begin{array}{l}\text { Cost Comparlson: } \\
20 \text { Gallon Pressure Vessels }\end{array}$ & $\begin{array}{r}\text { Vessel \#1 } \\
1500 \mathrm{psi}\end{array}$ & $\begin{array}{r}\text { Vessel } \$ 2 \\
5000 \text { psi }\end{array}$ \\
\hline Inside Radius, in & 9 & 9 \\
\hline Maximum Allowable Working Pressure (MAWP), psI & 1500 & 5000 \\
\hline Joint Elficlency, EJ & 1 & 1 \\
\hline Stress Value, psl & 20000 & 20000 \\
\hline Thickness, in & 0.71 & 2.65 \\
\hline Outside Radlus, in & 9.71 & 11.65 \\
\hline Height, Inside, In. & 18.15 & 18.15 \\
\hline Vessel Mat'l Volume, cu. In. & 1172.36 & 5372.56 \\
\hline Mass of Materlal Required, Ib & 331.78 & 1520.43 \\
\hline Ellective wt. for Vertical Mount & 381.55 & 1748.50 \\
\hline $\begin{array}{l}\text { Base cost } \\
\text { (based on Carbon steel } 1 \text { ATM) }\end{array}$ & 10.60 & 6.32 \\
\hline Material Factor & 4.3 & 4.3 \\
\hline Cost/b of vessel weight using SS316 & 45.59 & 27.17 \\
\hline Pressure Factor & 5.4 & 13.8 \\
\hline Cost Ib & 246.17 & 374.91 \\
\hline Total cost & $\$ 93,923$ & $\$ 655,536$ \\
\hline
\end{tabular}

Notice that vessel \#2, having a pressure rating 3.3 times higher than vessel \#1, costs nearly 7 times as much. This far outweighs the cost of incorporating a means of agitation in the smaller vessel. 
Work is continuing to characterize contaminants and to accurately measure the solvent velocity as a function of impeller speed. Ultimately, we want to be able to be able to specify process conditions based on general contaminant properties. To do this, we are characterizing both the poly(dimethyl)siloxane and the poiybutene/mineral oil mixture and will attempt to correlate this information to the conditions necessary for optimal clearing. Properties such as solubility, chemical composition, viscosity, and vapor pressure will be among those examined. Testing of the validity of our correlation will be done using a contaminant with different characteristics than either the poly(dimethyl)siloxane and the polybutene/mineral oil mixture. Velocities in the autoclave draft tube will be measured using a hot-wire anemometry technique. Calibration will be done with water through the same size diameter tube as the draft tube diameter, using a conventional metering device.

We plan additional work to correlate the effects of agitation, pressure, and power requirements on cleaning costs. Also, because the fiber optic/laser work used the fiber tip as the cleaning surface, we plan to investigate cleaning effects for large surfaces in real-time.

\section{REFERENCES}

[1] McHugh, M.A. and V.J. Krukonis. 1986. Supercritical Eluid Extraction: Principles_and Practice. Butterworth Publishers, Stoneham, Massachusetts.

[2] Motyl, K.M. 1988. Cleanine Studies of Metal Substrates Using Liquid/Supercritical Eluid Carbon Dioxide. Rockwell International, Rocky Flats Plant, Golden, Colorado.

[3] Johnstone, R.E.; Thring, M. W. 1957. Pilot Plants Models and Scale-up Methods in Chemical Engineering. McGraw-Hill: New York.

[4] Phelps, M.R., W.A. Wilcox, L.J. Silva, and R.S. Butner. 1993. Effects of Fluid Dynamics on Cleaning Efficacy of Supercritical Eluids. Pacific Northwest Laboratory, Richland, Washington. PNL-8579.

15] Perry, R.H. and D. Green. 1984. Perry's Chemical Engineers' Handbook Sixth Edition. McGraw Hill, New York.

[6] Holmes, D.B., R.M. Voncken, and J.A. Dekker. 1964. Eluid Elow in Turbine-Stirred. Baffled Tanks--I. Chemical Engineering Science, Volume 19, pp 201-208.

[7] Pressure Products Industries, Bulletin PDU-700.

[8] Peters, M.S. and K.D. Timmerhaus. 1991. Plant Designand Economics for Chemical Engineers. McGrawHill: New York. 

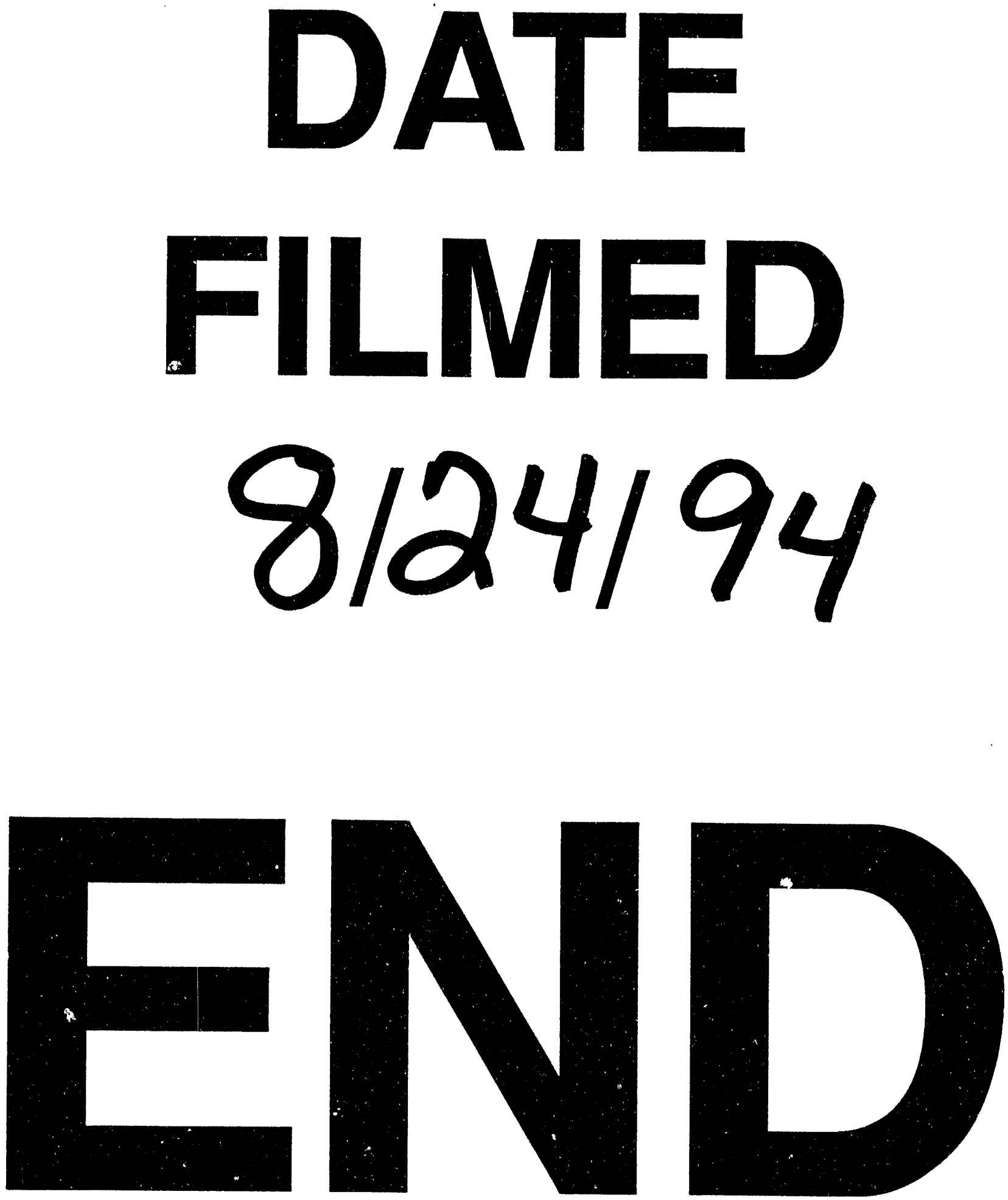
